\title{
Enemies of Democracy? \\ An exploration of the relationship between the authoritarian predisposition and attitudes toward democracy
}

-Kris Dunn, School of Politics and International Studies, University of Leeds

Abstract: Historically, authoritarianism has been synonymous with a fascistic or antidemocratic personality or outlook. The idea that the more authoritarian are hostile to democratic governance has continued from the first incarnation of the concept through to the more recent conceptualization of authoritarianism as a values orientation concerned with the trade-off between social conformity and individual autonomy. The research reported here explores how authoritarianism, as a values orientation, relates to attitudes toward democracy. Given the 'dynamic' relationship theorized between authoritarianism and social and political attitudes, this research also looks into whether and how perceived threat and societal views of democracy moderate the relationship between authoritarianism and attitudes toward democracy. Findings from analyses of data from Wave 6 or the World Values Survey indicate that 1.) authoritarianism is positively related to more favorable views of democracy; 2.) greater perceived threat is related to a more favorable view of democracy among the more authoritarian, while the more libertarian exhibit little variation across perceived threat; and 3.) aggregate support for democracy does not significantly change the relationship between authoritarianism and attitudes toward democracy. The importance of these findings on the literature and the current political events are discussed.

Keywords: Authoritarian Predisposition; Perceived Threat; Democratic Norms;

Importance of Democracy 
Theory regarding the authoritarian personality developed in response to concerns about popular support for or complacency toward the rise of post-World War I fascist and totalitarian regimes. Such concerns led researchers to examine anti-democratic impulses among democratic citizens (cf., Adorno et al. 1950; Fromm 1941; Lipset 1960). Though there was a lingering but less urgent sense of this in the work of Altemeyer (1996) in the nineteen-nineties and Stenner (2005) in the two-thousands, recent events such as the electoral success of the populist radical right in parts of Europe, Brexit in the U.K., and the election of Tea Party-associated representatives and Donald Trump in the U.S. has provoked renewed concern that modern, democratic institutions are not on as stable ground as we might assume, or hope. One consequence of these illiberal-seeming trends in established democracies is a renewed focus on the role of authoritarian individuals in the politics of Western democracies (e.g., MacWilliams 2016; Dunn 2015; Federico et al. 2017; Weiner and Federico 2017; Singh and Dunn 2015; Cizmar et al. 2014; Gordon 2017; Dunn 2020b).

Until recently, much of the concern in the authoritarianism literature focused on the intolerance and punitiveness frequently expressed by authoritarians toward outgroups. The principle concern being that intolerance in the electorate will find its way into office and thereafter into intolerant and punitive policy that may undermine democratic governance (Dunn and Singh 2011; Singh and Dunn 2015). While there is certainly reason for concern over how the presence and activity of authoritarians may impact governance, this paper takes a step back to examine a more fundamental question that seems to underlie much of this research: are authoritarians inherently opposed to democracy? In particular, I examine whether, given the more recent conceptualization of 
authoritarianism as a values orientation (e.g., Feldman and Stenner 1997), authoritarians are more hostile toward democracy in the abstract than are their polar, libertarians.

It is well-established that authoritarians are less committed to democratic norms of tolerance than are libertarians, though these norms certainly have at least some positive impact in how authoritarians respond to outgroups (Oyamot et al. 2017; Dunn 2014; Oyamot et al. 2012). What we do not know at this point is how authoritarians feel toward democracy per se. Based on the common characterization of authoritarians as the natural enemies of democracy and libertarians as the advocates of such, there is certainly reason to expect a fairly large difference in how these ideal-groups feel about democracy. The reflexive assumption suggests that libertarians are positively oriented toward democracy while authoritarians are negatively oriented toward democracy. However, authoritarians are more sensitive to norms than the average person (e.g., Altemeyer 1996). Authoritarians' attitudes toward democracy may, then, be a function of broader societal views about the value of democratic governance.

This article examines the relationship between authoritarianism and attitudes toward democracy while accounting for potential moderating effects from certain societal and individual characteristics. In the next section of this article, I briefly present current theory on authoritarianism and what expectations regarding attitudes toward democracy might arise from such. Following from this, I present the data and concept measurement used to examine the relationships suggested in the previous section. Next, I present the multi-level analyses of the data. Finally, I conclude the article with a discussion of how the findings herein are relevant to the broader literature. 


\section{The Authoritarian Predisposition and Attitudes toward Democracy}

The precise conceptualization of authoritarianism has changed fairly considerably over time; from the psychoanalytic perspectives of Fromm (1941) and Adorno et al. (1950) through the more attitudinal perspectives of Altemeyer $(1981,1988,1996)$ and Duckitt $(1989,2015)$ to the values-oriented and threat-interactive perspectives of Feldman and Stenner (Feldman and Stenner 1997; Feldman 2003; Stenner 2005) and Hetherington and colleagues (Hetherington and Suhay 2011; Hetherington and Weiler 2009). There are currently two dominant conceptualizations of authoritarianism that are commonly referenced in the literature. These draw either on the foundational work of Altemeyer (1981) or on that of Feldman and Stenner (1997). The former conceptualizes authoritarianism as an attitude dimension; the equivalent of social conservatism (Duckitt 2015). The latter considers authoritarianism to be a values orientation that predisposes one toward intolerance and punitiveness (Stenner 2005, 2009). This article focuses on the latter conceptualization of authoritarianism.

Authoritarianism is a values-orientation concerned with the trade-off between social conformity and individual autonomy. This orientation is anchored on one end by authoritarians, those who prioritize social conformity over individual autonomy, and on the other by libertarians, those who prioritize individual autonomy over social conformity. Importantly, and diverging from previous characterizations, this conceptualization of authoritarianism is not a personal disposition (i.e., one's current socio-cultural attitudes), but a predisposition toward intolerance and punitiveness when the perceived wellbeing of the ingroup is threatened. 
The primary difference between authoritarians and libertarians is their reactivity to threat. Those who fall on the authoritarian side of the continuum seem to perceive threat to the wellbeing of the ingroup as a matter of course; there appears to always be some threat or another to the wellbeing of the ingroup (Hetherington and Weiler 2009). Authoritarians are therefore more likely to express intolerant and punitive attitudes as a matter of routine. Those who fall on the libertarian side of the continuum, on the other hand, are less susceptible to threat. Yet, when they do feel threatened, they also become more intolerant and punitive (Hetherington and Weiler 2009). ${ }^{1}$

A great deal of past research on authoritarianism focuses on intolerance and punitiveness and tells us very little about potential attitudes toward democracy per se; expectations regarding authoritarians' attitudes toward democracy are therefore derived from theory regarding democracy. As noted by Dunn and Singh (Dunn 2014; Singh and

\footnotetext{
${ }^{1}$ How individuals react to threat is markedly different in Feldman and Stenner's (1997) theory than in Hetherington and Weiler's (2009). Stenner's (2005) theory of the authoritarian predisposition predicts and finds evidence for a positive interaction between authoritarianism and threat where the more and less authoritarian become attitudinally more different when they perceive a (normative) threat to the ingroup. Hetherington and Weiler (2009) predict and find evidence that the more and less authoritarian become attitudinally more similar when they perceive a threat. As suggested by Hetherington and Weiler (2009), this seems to be due to how the different authors operationalize threat. Feldman and Stenner's operationalization of threat is assumed, i.e. they assume that the stimuli are threatening to both groups. However, there is reason to believe that, in general, their threat measures are primarily threatening to the more authoritarian and are actually a positive reinforcement for the more tolerant and equanimous attitudes of the less authoritarian. Hetherington and Weiler (2009), on the other hand, rely on data that specifically asks whether the respondents feel threatened.
} 
Dunn 2013; Dunn and Singh 2014), pluralism and tolerance of such is fundamental to democracy. Authoritarians, then, who tend toward intolerance of dissent and diversity, should dislike democracy. The more libertarian, on the other hand, who are usually more tolerant and equanimous, should embrace modern democracy and its pluralistic nature.

If perceived threat acts on individual attitudes toward democracy in the same fashion as it does on tolerance and punitiveness, the attitudes toward democracy of the more authoritarian would be unaffected by any stated change in their level of perceived threat from any specific source as they are likely to feel threatened from some source or another regardless of how they feel about any specific threat. Libertarians who report feeling threatened, however, will be more likely to express less favorable attitudes toward democracy as that perceived threat increases, to the point that their attitudes toward democracy may be indistinguishable from the most authoritarian.

The problem with the above perspective is that it largely ignores the influence of societal norms on people in general (cf., Etzioni 2000) and the hyper-normative nature of the more authoritarian specifically. Simply put, the above completely ignores any context which may be relevant to the discussion; and context certainly matters for how we think about governance and democracy more specifically (e.g., Welzel 2013; Bratton and Mattes 2001; Dalton et al. 2007). As the more authoritarian are more norm adherent than average (Altemeyer 1996; Oyamot et al. 2012; Oyamot et al. 2017; Dunn 2014), in countries where democracy is widely accepted and believed the only legitimate form of governance, the more authoritarian are likely to be just as favorably oriented toward democracy as the more libertarian, if not more so; at least in the abstract. 
This suggests a disconnect between abstract and concrete attitudes. In the abstract the more authoritarian can be reasonably expected to be favorably oriented toward democracy where democracy is the normatively-preferred form of governance. However, a substantial volume of literature demonstrates that authoritarians are less committed to the more concrete applications of such governance - such as moral, racial/ethnic, and political tolerance. In other words, while authoritarians are clearly less tolerant of the dissent and diversity inherent to democracy, we may nevertheless expect authoritarians to be supportive of democracy in the abstract due to prevailing norms. Such a disconnect between concrete aspects of democracy and the abstract concept itself has already been documented in the literature (e.g., Prothro and Grigg 1960; McClosky 1964; Chong 1993; McClosky and Zaller 1984) and those with more authoritarian attitudes are more prone to this cognitive inconsistency than the average person (Altemeyer 1996). It should therefore not be surprising if we find that the more authoritarian are highly intolerant of dissent and diversity while enthusiastically embracing democracy.

There is a similar concern for how the more libertarian may feel about democracy. While we might expect those who prefer individual autonomy to social conformity and tend to be tolerant of outgroups to be supportive of democracy, we cannot ignore the effects that societal norms may exert on the more libertarian; libertarians in societies with less favorable views of democracy may very well also express less favorable views of democracy than they would in more democratic societies. Nor can we ignore the possibility that those with a preference for individual autonomy over social conformity may be more demanding, and therefore critical, of democracy in general (cf., Dunn et al. 2017; Welzel 2013). 
Combining considerations of threat and societal norms further complicates this already complicated picture. To my knowledge, there has been no discussion that addresses how norms may condition how threat moderates the relationship between authoritarianism and attitudes. However, we can generate at least one theoretical argument related to such: if there is a smaller variation in attitudes toward democracy in countries with more favorable attitudes toward democracy, then it is likely that threat exerts a decreasing impact on the relationship between authoritarianism and attitudes toward democracy as aggregate favorability toward democracy increases. In other words, as norms become more widely embraced, the differences between the more authoritarian and the more libertarian become increasingly small and presents less of a gulf for threat to work to reconcile. This, of course, assumes that the relationship between authoritarianism, threat, and attitudes toward democracy roughly reflects the relationship between authoritarianism, threat, and tolerance toward outgroups.

Given the current state of the literature and the specific considerations that must be taken into account - such as the more norm-adherent orientation of the more authoritarian and the potentially more critical nature of the more libertarian - when considering the relationship between authoritarianism and attitudes toward democracy, there appears to be reasoning to support contradictory hypotheses. For example: should the potentially more norm-adherent orientation of the more authoritarian and more critical nature of the more libertarian lead us to expect that the more authoritarian might actually offer a more favorable opinion of democracy than the more libertarian? Given the potential for various contradictory hypotheses, this article aims to explore the relationship between 
authoritarianism and attitudes toward democracy instead of testing a myriad of conflicting hypotheses.

Though I forgo formulating specific hypotheses, the above discussion does suggest two concepts that are likely relevant to the relationship between authoritarianism and attitudes toward democracy: an individual's level of perceived threat and a society's normative view of democracy. As such, the effects of these two concepts will be explored alongside the relationship between authoritarianism and attitudes toward democracy.

\section{Method}

\section{Sample}

The following analyses rely on data from the $6^{\text {th }}$ wave of the World Values Survey (Inglehart et al. 2014) ${ }^{2}$ and the Freedom House Freedom in the World reports (Freedomhouse.org 2018) ${ }^{3}$. The WVS draws a representative sample of at least 1000 respondents between the ages of 18 and 85 for each country involved in the study. Full probability sampling is done where resources allow; otherwise, strictly governed quota sampling, or some combination thereof, is used. Interviews are conducted face-to-face and every reasonable effort is made to reduce non-response. The $W_{V} S_{6}$ surveys 60 countries between the years 2010 and 2014. Missing data reduces the sample to 55 countries and 67,831 individuals. ${ }^{4}$

\footnotetext{
2 Data can be found at: http://www.worldvaluessurvey.org.

${ }^{3}$ Data can be found at: https://freedomhouse.org/report-types/freedom-world.

4 The countries included in the study, along with the year in which the country was initially surveyed, are:
} Algeria 2014, Argentina 2013, Armenia 2011, Australia 2012, Azerbaijan 2011, Belarus 2011, Brazil 2014, 


\section{Measures}

Importance of Democracy: The dependent variable in the following analyses formulates a respondent's attitude toward democracy based on the importance they assign to living in a democracy. The question asks, on a scale from 1 to 10 , "How important is it for you to live in a country that is governed democratically?" The variable is recoded to range from 0 to 1 , with a higher score indicating that it is more important for the respondent to live in a democracy.

Aggregate Importance of Democracy: The above discussion indicates that the relationship between authoritarianism and personal attitudes toward democracy may be dependent on societal attitudes toward democracy. To account for this, I derive the mean value for each country sample for the Importance of Democracy variable. This variable initially ranged from 0.71 to 0.93 indicating that, on average, the sample for each country views living in a democracy as rather important, an unsurprising finding given past research on this topic (e.g., Norris 1999). To provide a meaningful 0-value and make the intercepts and interactions that appear in the following analyses somewhat more

Chile 2011, China 2012, Cyprus 2011, Ecuador 2013, Egypt 2013, Estonia 2011, Georgia 2014, Germany 2013, Ghana 2011, Hong Kong 2013, India 2012, Iraq 2013, Japan 2010, Jordan 2014, Kazakhstan 2011, South Korea 2010, Kyrgyzstan 2011, Lebanon 2013, Libya 2013, Malaysia 2011, Mexico 2012, Morocco 2011, Netherlands 2012, New Zealand 2011, Nigeria 2011, Pakistan 2012, Palestine 2013, Peru 2012, Philippines 2012, Poland 2012, Romania 2012, Russia 2011, Rwanda 2012, Singapore 2012, Slovenia 2011, South Africa 2013, Spain 2011, Sweden 2011, Taiwan 2012, Thailand 2013, Trinidad and Tabago 2010, Tunisia 2013, Turkey 2011, Ukraine 2011, United States 2011, Uruguay 2011, Yemen 2013, Zimbabwe 2011. 
interpretable, I recoded this variable to range from 0 to 1 . A higher value indicates a higher aggregate value assigned to living in a democracy.

Democratic Tenure: To ensure that the aggregate importance of democracy is not simply a reflection of the duration a country has been a democracy, and therefore to prevent confounding societal views with democratic tradition, I also control for the duration a country has been a democracy. This measure is the consecutive number of years a country has been rated free since 1973 by the Freedom House Freedom in the World Reports and ranges from 0 to 40 . This variable is moderately correlated $(r=0.480, p<$ $0.01, n=55)$ with the Aggregate Importance of Democracy measure.

Authoritarianism: As previously noted, following previous research in this area, I conceive of authoritarianism as a values orientation; one concerned with the relative balance between social conformity and individual autonomy. To measure this concept, I follow Feldman (2003) in constructing my measure of authoritarianism; specifically, his construction of the SCA-V (social conformity - autonomy values) measure. Using the Schwartz (2012) 10-item values inventory included in the WVS $_{6}$, I average each individual's scores on the stimulation and self-direction values items to produce the Individual Autonomy scale. I do the same for the conformity and tradition values items to produce the Social Conformity scale. Each scale ranges from 1 to 6 with a higher score indicating a higher reported identification with that value cluster. I then subtract the Individual Autonomy scale from the Social Conformity scale. This produces an authoritarianism scale ranging from -5 to +5 . Those scoring below 0 , the midpoint of the scale, prioritize individual autonomy over social conformity, while those who score above 0 prioritize social conformity over individual autonomy. Those who score precisely 0 
prioritize neither. Higher scores on this scale indicate a greater degree of authoritarianism, while lower scores indicate a greater degree of libertarianism. Invariance analyses of this scale have demonstrated that this measure is configurally invariant across a wide variety of countries, including those used in the following analyses (Dunn et al. 2020).

Perceived Threat: This variable draws on a question which asks respondents the degree to which they are worried about the following four events: "A war involving my country", "A terrorist attack", "A civil war", "Government wire-tapping or reading my mail or email". Respondents are given four response categories: "Not at all", "Not much", "A good deal", "Very much". The four variables are averaged and recoded to range from 0 to1. Higher values on this measure correspond to a greater level of perceived threat. This measure demonstrates configural and partial-metric invariance across a wide variety of countries, including those used in the following analyses (Dunn et al. 2020).

Control Variables: In the following analyses, I control for age, education, income, political interest, sex, and the aforementioned duration a country has been a democracy. All control variables are coded to range from 0 , to facilitate the interpretation of intercepts. Age is a measure of the respondent's reported age ranging from 18 to 99; recoded to range from 0 to 81 . Education is a variable derived from a question inquiring in to the respondent's highest level of education; ranging from 0 (no formal education) to 6 (university-level education, with degree). Income is a measure of the respondent's household income level in terms of country-specific income ranges; ranging from 0 to 9 with a higher value indicating a higher household income. Political interest is a reflective scale composed of two items indicating the respondent's interest in politics: "how 
important [is politics] in your life" and "how interested would you say you are in politics". These variables are averaged and recoded to provide a single measure of political interest ranging from 0 to 1 with a higher score indicating a greater interest in politics. Sex is coded by the interviewer as either male or female based on their observation of the respondent: male is coded as 0 ; female as 1 .

\section{Results}

The following analyses use a multi-level, random-effects regression model. An intercept-only model of the data indicates that approximately $5 \%$ of the variation in the Importance of Democracy variable is attributable to country-level differences. This indicates the non-independence of within-country observations. Multilevel models account for the non-independence of within-country observations and allow for the simultaneous analysis of both individual-level and country-level variables without falsely inflating the significance of the country-level variables. The random-effects specification assumes that any variation in the slopes of the IVs across countries is due to true variation, not merely estimation error. I expect true variation in the slope of authoritarianism across countries as the threat measure used here may not capture all relevant specific threats or fully eclipse potential background threat (cf., Dunn 2014).

The analyses proceed in the following order. First, I present a non-interactive model (Table 1, Model A). In this model all above-mentioned variables are included but are assumed to demonstrate purely additive effects on the dependent variable. This model allows a simplistic (i.e., noninteractive) examination of how authoritarianism is related to the importance of democracy. Second, I present a model including a bivariate interaction between authoritarianism and threat (Table 1, Model B) to analyze whether 
threat moderates the relationship between authoritarianism and importance of democracy. Third, I present a model including a trivariate interaction between authoritarianism, threat, and the aggregate level of importance of democracy in a country (Table 1, Model C) to examine whether aggregate perceptions of the importance of democracy moderates the relationship between the authoritarianism/threat interaction and importance of democracy.

\begin{tabular}{|c|c|c|c|c|c|c|c|c|c|}
\hline & \multicolumn{3}{|c|}{ Model A } & \multicolumn{3}{|c|}{ Model B } & \multicolumn{3}{|c|}{ Model C } \\
\hline & $\beta$ & s.e. & $p$ & $\beta$ & s.e. & $p$ & $\beta$ & s.e. & $p$ \\
\hline authoritarianism & 0.010 & 0.001 & 0.000 & 0.007 & 0.001 & 0.000 & 0.006 & 0.003 & 0.022 \\
\hline threat & 0.030 & 0.003 & 0.000 & 0.027 & 0.003 & 0.000 & 0.055 & 0.006 & 0.000 \\
\hline aggregate importance & 0.210 & 0.004 & 0.000 & 0.209 & 0.004 & 0.000 & 0.242 & 0.007 & 0.000 \\
\hline auth * threat & -- & -- & -- & 0.005 & 0.002 & 0.004 & 0.006 & 0.004 & 0.150 \\
\hline auth * agg imp & -- & -- & -- & -- & -- & -- & 0.002 & 0.004 & 0.682 \\
\hline threat * agg imp & -- & -- & -- & -- & -- & -- & -0.061 & 0.011 & 0.000 \\
\hline auth * threat * agg imp & -- & -- & -- & -- & -- & -- & 0.000 & 0.007 & 0.984 \\
\hline age & 0.001 & 0.000 & 0.000 & 0.001 & 0.000 & 0.000 & 0.001 & 0.000 & 0.000 \\
\hline education & 0.011 & 0.001 & 0.000 & 0.011 & 0.001 & 0.000 & 0.011 & 0.001 & 0.000 \\
\hline income & 0.003 & 0.000 & 0.000 & 0.003 & 0.000 & 0.000 & 0.003 & 0.000 & 0.000 \\
\hline political interest & 0.059 & 0.003 & 0.000 & 0.059 & 0.003 & 0.000 & 0.058 & 0.003 & 0.000 \\
\hline sex (female) & -0.004 & 0.002 & 0.025 & -0.004 & 0.002 & 0.026 & -0.004 & 0.002 & 0.028 \\
\hline democratic tenure & 0.000 & 0.000 & 0.689 & 0.000 & 0.000 & 0.696 & 0.000 & 0.000 & 0.465 \\
\hline constant & 0.595 & 0.004 & 0.000 & 0.597 & 0.004 & 0.000 & 0.582 & 0.005 & 0.000 \\
\hline
\end{tabular}

Table1, Model A demonstrates that authoritarianism is positively related to importance of democracy; the coefficient being $0.010(\rho<0.001)$. In other words, the 
more authoritarian the individual, the more important one judges democracy to be. While the substantive impact on authoritarianism on importance of democracy here is not overwhelming, the most authoritarian place themselves $10 \%$ higher on the scale than do the most libertarian, all else equal, demonstrating a substantive impact of authoritarianism on importance of democracy.

\begin{tabular}{|c|c|c|c|}
\hline \multicolumn{4}{|c|}{$\begin{array}{l}\text { Table 2: marginal effects of } \\
\text { authoritarianism over threat }\end{array}$} \\
\hline threat $=$ & $\beta$ & s.e. & $p$ \\
\hline 0 & 0.007 & 0.001 & 0.000 \\
\hline 0.25 & 0.008 & 0.001 & 0.000 \\
\hline 0.5 & 0.009 & 0.001 & 0.000 \\
\hline 0.75 & 0.011 & 0.001 & 0.000 \\
\hline 1 & 0.012 & 0.001 & 0.000 \\
\hline
\end{tabular}

Table 1, Model B demonstrates a significant interaction between authoritarianism and threat. To facilitate interpretation of this interaction, Table 2 provides a more detailed list of slopes for authoritarianism for five values of threat: $0,0.25,0.5,0.75$, and 1 . One point of note is that this table relays the same information as in Model A: authoritarianism is positively related to importance of democracy. Further, over the range of threat, the slope on authoritarianism increases from 0.007 (at threat $=0$ ) to 0.012 (at threat $=1$ ), demonstrating a stronger relationship as threat increases. At the lowest levels of threat, the difference between the most libertarian and the most authoritarian is approximately $7 \%$ of the importance of democracy scale; at the highest levels of threat the difference is approximately $12 \%$ of the scale. 
Dependent Variable: Democracy Important

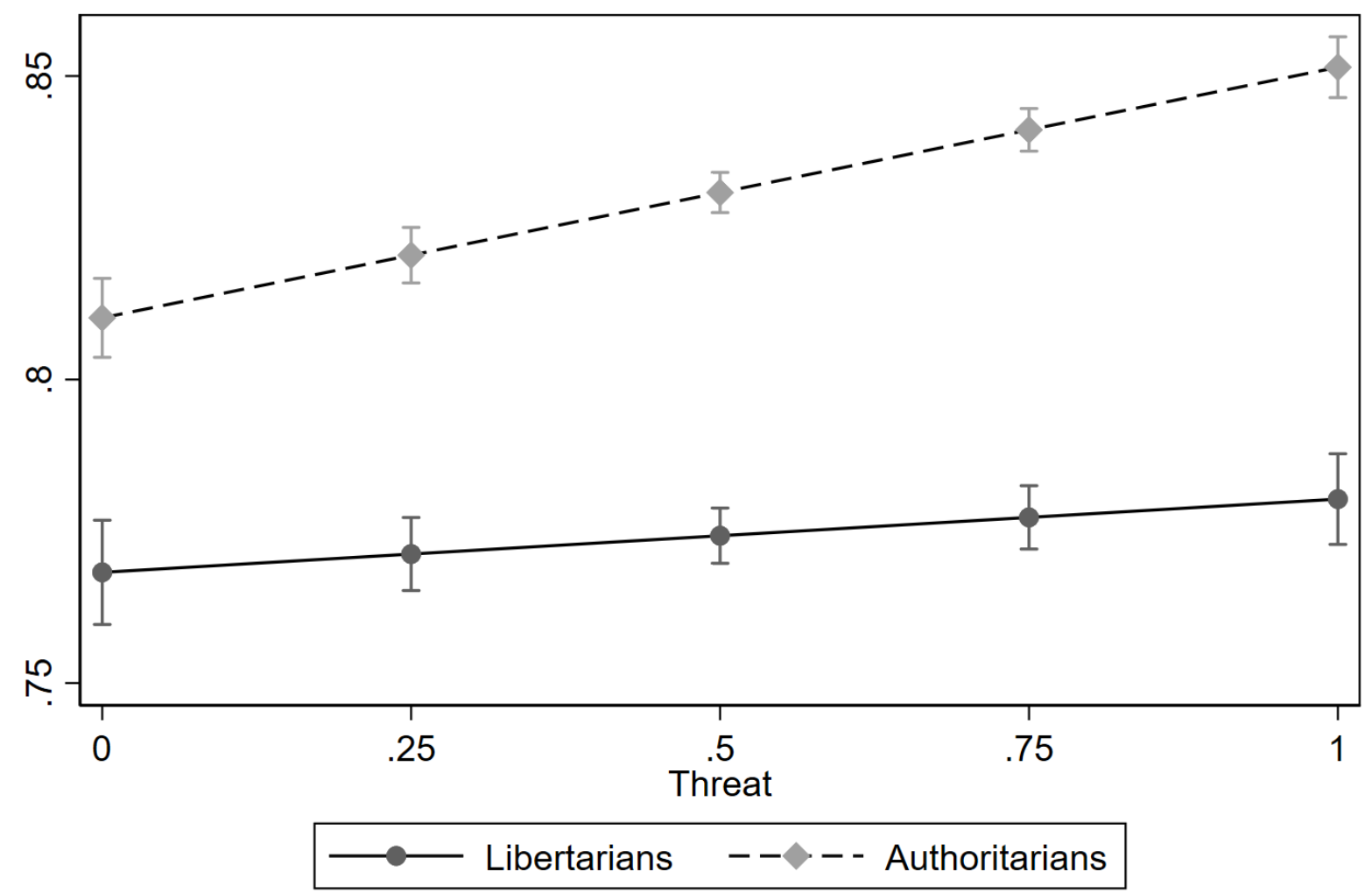

Figure 1: Predicted scores of importance of democracy for libertarians and authoritarians over the range of threat.

To further assist in the substantive interpretation of this interaction, Figure 1 provides a visual representation of this relationship. Figure 1 plots the values of importance of democracy for those who score at 3 and -3 on the authoritarianism scale ${ }^{5}$;

\footnotetext{
${ }^{5}$ The use of 3 and -3 is a somewhat arbitrary decision. The choice was made simply to illustrate how someone with a more authoritarian score differs from someone with a more libertarian score. If one considers those ranging from -5 to -1 on the scale to be libertarian, those between -1 and 1 to be neither libertarian or authoritarian, and those from 1 to 5 on the scale to be authoritarian, -3 and 3 are the midpoint for each categorical range.
} 
the former being more authoritarian and the latter being more libertarian. This figure illustrates that the increase in the slope on authoritarianism is due to the increasing importance the more authoritarian place on democracy as threat increases. The difference in the point-to-point estimates of libertarians is a non-significant 0.012 ( $\rho=$ $0.075)$ between those reporting the lowest and the highest levels of perceived threat. The same comparison for authoritarians is a significant $0.041(\rho<0.001)$. The greater slope on authoritarianism corresponding with a greater perception of threat is therefore driven by the more authoritarian who attach more importance to democracy the more threatened they feel; the more libertarian remain rather static in their valuation of the importance of democracy.

Model $\mathrm{C}$ of Table 1 demonstrates an insignificant trivariate interaction between authoritarianism, threat, and aggregate perceptions of democracy. As Table 2 did for Model B, Table 3 provides a more detailed look at the interaction in Model C. Similar to Table 2, Table 3 provides the slopes on authoritarianism across five values of threat. In addition, the 3 panels break this relationship down by three values of aggregate perceptions of democracy: 1 standard deviation below the mean $(0.27)$, the mean $(0.51)$, and 1 standard deviation above the mean $(0.75) \cdot{ }^{6}$ As is apparent from the table, there is no substantive difference between the three panels. Nor is there any substantive difference between these three panels and the output displayed in Table 2. Aggregate

\footnotetext{
${ }^{6}$ These values were determined using each country as a single observation. These scores are not influence by the number of individual-level observations in each country.
} 
perceptions of democracy therefore do not moderate the relationship between the authoritarianism/threat interaction and importance of democracy.

Table 3: marginal effects of authoritarianism over threat and mean importance of democracy

\begin{tabular}{c|ccc|ccc|ccc|}
\cline { 2 - 9 } threat $=$ & \multicolumn{4}{|c|}{ aggregate score $=0.27$} & \multicolumn{4}{|c|}{ aggregate score $=0.51$} & \multicolumn{3}{|c|}{ aggregate score $=0.75$} \\
$\beta$ & s.e. & $p$ & $\beta$ & s.e. & $p$ & $\beta$ & s.e. & $p$ \\
\cline { 2 - 9 } & 0.006 & 0.002 & 0.000 & 0.007 & 0.001 & 0.000 & 0.007 & 0.001 & 0.000 \\
0.25 & 0.008 & 0.001 & 0.000 & 0.008 & 0.001 & 0.000 & 0.009 & 0.001 & 0.000 \\
0.5 & 0.009 & 0.001 & 0.000 & 0.010 & 0.001 & 0.000 & 0.010 & 0.001 & 0.000 \\
0.75 & 0.011 & 0.001 & 0.000 & 0.011 & 0.001 & 0.000 & 0.011 & 0.001 & 0.000 \\
1 & 0.012 & 0.001 & 0.000 & 0.012 & 0.001 & 0.000 & 0.013 & 0.001 & 0.000 \\
\hline
\end{tabular}

Though aggregate perceptions of democracy does not alter the value of the coefficient on the authoritarianism/threat interaction, it may still alter the pattern of the relationship between authoritarianism and importance of democracy: which categorical group drives the relationship could change without altering the coefficient on the authoritarianism-threat interaction. To examine this possibility, Figure 2 provides an illustration of the trivariate interaction. Each panel in the figure corresponds to the same aggregate importance of democracy value in the panels of Table 3. As with Figure 1, Figure 2 also uses the values of -3 and 3 to represent libertarians and authoritarians, respectively. As one would expect, given the increase in the aggregate score, the authoritarianism/threat interaction orients around a higher average importance of democracy score. However, unlike the story extracted from Table 3, Figure 2 does demonstrate a slight change in the pattern of the authoritarianism/threat interaction. While the slopes on authoritarianism may remain the same across these three panels, the relationship between authoritarianism and attitude toward democracy subtly shifts. In 
effect, both lines rotate clockwise around their midpoint as one moves from left to right across the panels. This maintains the slope while subtly adjusting how much each side of the scale drives the relationship. In the first panel, the difference between libertarians expressing minimal threat and those expressing maximal threat is a significant 0.022 ( $\rho$ $=0.017)$. This shifts to a nonsignificant $0.007(\rho=0.286)$ in panel 2 and $-0.007(\rho=0.452)$

in panel 3. For authoritarians, in the first panel, the difference is a significant 0.056 ( $\rho<$ $0.001)$. This shifts to a still significant $0.041(\rho<0.001)$ in panel 2 and $0.027(\rho<0.001)$ in panel 3. The difference between the lines at minimal and maximal threat remains at approximately 0.040 and 0.074 , respectively, across the panels. Though this figure does reveal some variation in the details of the interaction, this variation does not change the overall story: authoritarians largely drive the increased strength of the relationship between authoritarianism and importance of democracy over the range of threat by valuing democracy more when perceived threat is greater.

\section{Discussion}

Initial discussions of authoritarianism were an attempt to uncover why democratic citizens would not only permit, but in some cases help overthrow democratic regimes (e.g., Fromm 1941; Adorno et al. 1950; Lipset 1959). In one of its earliest incarnations, authoritarianism was also referred to as a fascistic or anti-democratic personality (cf., Frenkel-Brunswik et al. 1947). The characterization of authoritarians as enemies of freedom (Altemeyer 1988), then, seems quite appropriate. More recent research that focuses on authoritarians' predisposition toward intolerance and punitiveness only serves to further the claim that authoritarians cannot possibly be supportive of democracy; after all, democracy, as a form of regime built on the ideas of diversity and dissent (e.g., Sartori 
1997; Markoff 2011), is completely antithetical to the unity and uniformity authoritarians prioritize (Stenner 2005).

\section{Dependent Variable: Democracy Important}
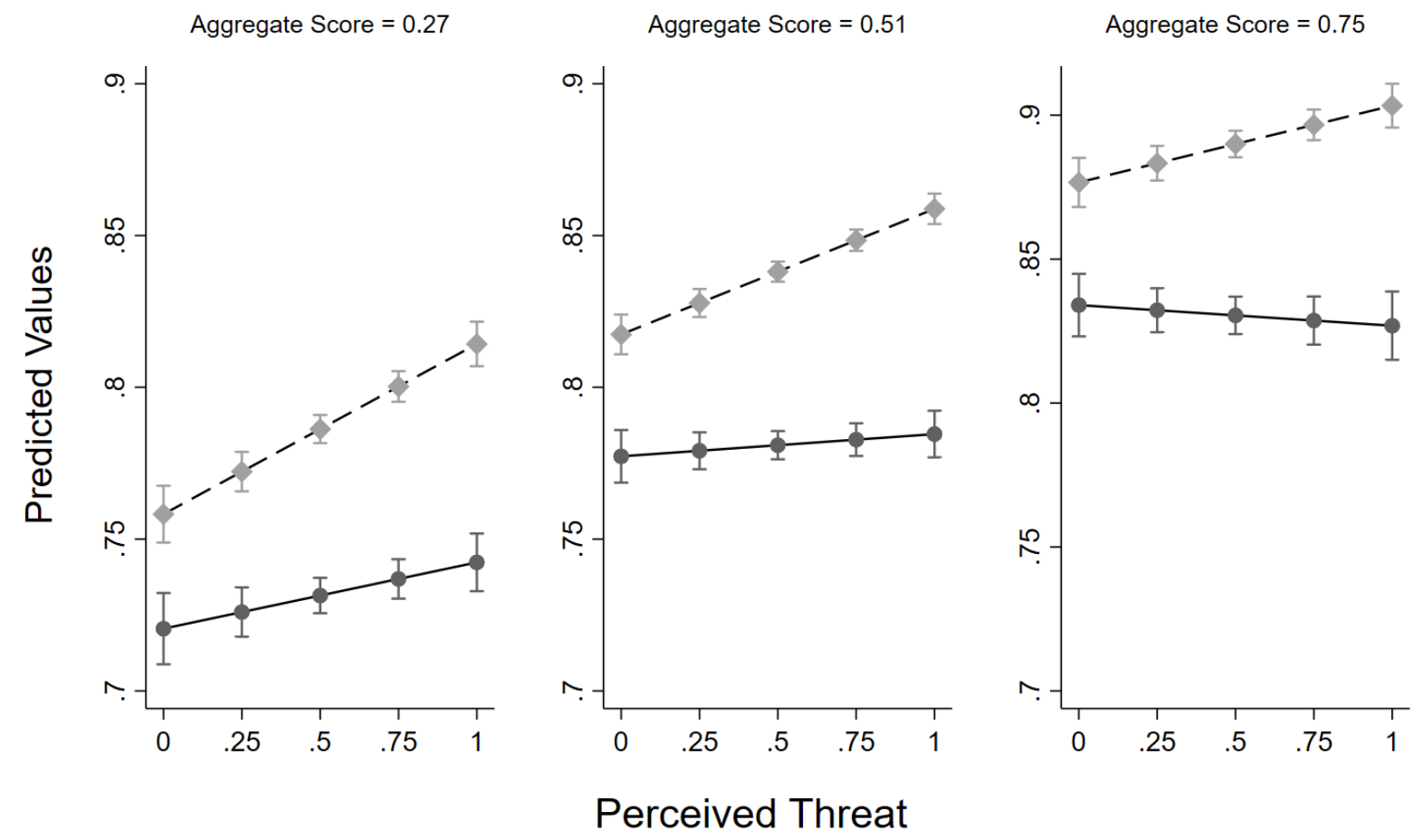

Figure 2: Predicted scores of importance of democracy for libertarians and authoritarians over the range of threat for three different values of aggregate importance of democracy.

Though a great deal of recent research has delved into the increasingly nuanced relationship between authoritarianism and intolerant and punitive attitudes, the early concerns regarding support for democracy itself have largely faded over time. With the increased success of the radical-right in a host of established democracies around the world (Inglehart and Norris 2017; Mudde 2013), however, concern over how (un)favorably citizens view democratic governance has once again become a focal issue (McCoy et al. 
2018; Wike and Fetterolf 2018). Given its intellectual heritage, it is unsurprising that authoritarianism has found a prominent place in this discussion. There are numerous questions that arise in response to this debate and investigation. Concerns over threats to the more liberal aspects of democracy, such as the various facets of tolerance and inclusion, are already well discussed in the authoritarianism literature as this is where the focus settled and largely remained throughout the last half-century. What this investigation seeks to elucidate is whether authoritarianism predicts support for democracy per se, and if so, is this support conditional? Analyzing data from the sixth wave of the World Values Survey, this article begins to examine these questions.

Previous literature indicates a number of possible relationships between authoritarianism and attitudes toward democracy, many of which are contradictory. Nevertheless, two concepts emerge from the literature as directly relevant to the discussion: perceived threat and societal norms regarding democracy. As such, and given the multilevel nature of the data, a random-effects multilevel model including a three-way interaction comprised of authoritarianism, perceived threat, and aggregate views as to the importance of democracy is constructed. The analyses reveal that, in general, authoritarians view democracy as more important than do libertarians. The strength of this relationship is conditional on threat but not on aggregate perceptions of the importance of democracy. Perceived threat increases the strength of this relationship with the more authoritarian the primary drivers of this increase; in other words, the more libertarian show remarkably little change across the range of perceived threat while the more authoritarian assign substantively more importance to living in a democracy as perceived threat increases. 
These findings indicate that the relationship between authoritarianism and attitudes toward abstract concepts such as democracy may not be as straightforward as those dealing with measures of tolerance of or punitiveness toward specific outgroups. The concept of democracy is an abstract, vaguely defined, and widely supported form of governance - even in those countries that one would stretch credulity to qualify as such (Norris 1999). As noted above, in the data used herein, even those countries with the least favorable views of democracy still rated democracy very favorably, scoring the importance of living in a democracy above 0.70 on a scale from 0 to 1 . In this light, for the more authoritarian, who are noted for their greater levels of norm adherence, their strongly positive attitude toward democracy makes sense, regardless of how they feel about the more concrete applications of such governance.

One point of particular interest in this finding is that threat does show an impact on the attitudes of the more authoritarian. Hetherington and Weiler (2009) suggest that the more authoritarian, in general, feel perpetually threatened, perhaps in a more generalized and abstracted fashion, regardless of any threat they may or may not feel from any specific source. This is their explanation for why authoritarians in their study report high levels of intolerance and low levels of support for civil liberties regardless of how threatened they feel by any specific group or event. The implication is that this generalized threat dominates any consideration of specific threat; that specific threat will have little impact on their attitudes as generalized threat already pushes the more authoritarian toward more socially conservative positions, leaving little room for specific threat to exert much additional impact. In this case, the more socially conservative position is a strengthened attachment to one's country's norms, i.e. a more favorable view of 
democracy. As there is clearly a substantive difference among the attitudes of the more authoritarian across the threat scale, this somewhat contradicts the assumption that the more authoritarian are already as threatened as they can be. That greater perceived threat does correspond with more favorable attitudes toward democracy in the more authoritarian but shows no discernable difference among the more libertarian, instead reinforces Stenner's (2005) idea that the more authoritarian are more likely to "man the barricades" when threatened; when threatened, the more authoritarian will more strongly support the perceived norms of their society. This research reinforces the need to clarify the obvious complexities in how people across the authoritarianism spectrum perceive and respond to threat.

Given the abstract nature of the concept of democracy, the obvious response to this research is to suggest that the more authoritarian differ from the more libertarian in their understanding of democracy. Previous research supports this view. However, it is not in the direction that one might expect. Dunn (2020a) presents evidence that, except in the most effectively democratic countries (cf., Alexander and Welzel 2011), the more authoritarian actually hold a more liberal understanding of democracy than do the more libertarian. However, as with this study, Dunn's research similarly relies on somewhat abstracted concepts: civil liberties and women's rights. There is convincing evidence that the more authoritarian are not more favorable toward more concrete examples of these concepts (Hetherington and Suhay 2011; Hetherington and Weiler 2009; Peterson and Zurbriggen 2010; Altemeyer 1996; Duncan et al. 1997).

Though there is little new in finding that attitudes toward abstract concepts and more concrete applications do not align (e.g., Prothro and Grigg 1960; McClosky 1964; 
Chong 1993; McClosky and Zaller 1984), a detailed explanation for this inconsistency and an analysis of the potential implications of such is certainly necessary. The rise in the popularity of illiberal parties within established democracies and the increase in illiberal democracies more broadly (e.g., Zakaria 1997; Rupnik 2016; Pappas 2016; Puddington et al. 2019) urge a more thorough examination of how individuals and groups understand and support democracy and what this means for the more concrete applications of democratic principles and norms. From a more normative perspective, one area of particular interest is whether the attachment of the more authoritarian to democracy in the abstract can be used as a lever to counter their more illiberal concrete preferences. 


\section{References}

Adorno, Theodor W., Else Frenkel-Brunswik, Daniel J. Levinson, and R. Nevitt Sanford. 1950. The authoritarian personality. 1st ed. New York: Harper.

Alexander, Amy C., and Christian Welzel. 2011. "Measuring Effective Democracy: The Human Empowerment Approach." Comparative Politics 43 (3):271-89.

Altemeyer, Bob. 1981. Right-Wing Authoritarianism. Winnipeg: University of Manitoba Press.

. 1988. Enemies of Freedom: Understanding right-wing authoritarianism. 1st ed. San Francisco: Jossey-Bass Publishers.

—. 1996. The authoritarian specter. Cambridge, MA: Harvard University Press.

Bratton, Michael, and Robert Mattes. 2001. "Support for Democracy in Africa: Intrinsic or Instrumental?" British Journal of Political Science 31 (03):447-74.

Chong, Dennis. 1993. "How people think, reason, and feel about rights and liberties." American Journal of Political Science 37 (3):867-99.

Cizmar, Anne M., Geoffrey C. Layman, John McTague, Shanna Pearson-Merkowitz, and Michael Spivey. 2014. "Authoritarianism and American Political Behavior from 1952 to 2008." Political Research Quarterly 67 (1):71-83.

Dalton, Russell J., Doh C. Shin, and Willy Jou. 2007. "Understanding Democracy: Data from unlikely places." Journal of Democracy 18 (4):142-56.

Duckitt, John. 1989. "Authoritarianism and group identification: A new view of an old construct." Political Psychology 10 (1):63-84.

— 2015. "Authoritarian Personality." In International Encyclopedia of the Social \& Behavioral Sciences, ed. J. D. Wright. Oxford: Elsevier. 
Duncan, Lauren E., Bill E. Peterson, and David G. Winter. 1997. "Authoritarianism and Gender Roles: Toward a Psychological Analysis of Hegemonic Relationships." Personality and Social Psychology Bulletin 23 (1):41-9.

Dunn, Kris. 2014. "Authoritarianism and Intolerance Under Autocratic and Democratic Regimes." Journal of Social and Political Psychology 2 (1):220-41.

_ 2015. "Preference for Radical Right-wing Populist Parties among Exclusivenationalists and Authoritarians." Party Politics 21 (3):367-80.

_ 2020a. "The Authoritarian Predisposition and Liberal Beliefs about Democracy." https://doi.org/10.31234/osf.io/qzn8w.

_ 2020b. "The Authoritarian Predisposition, Perceived Threat, and Trust in Political Institutions." https://doi.org/10.31234/osf.io/ewtdr.

Dunn, Kris, Evelyn Griffiths, Sarah Lamb, Rebecca Shortt, and Eleanor Theochari. 2017. "The Human Empowerment Sequence and the Development of Libertarian Values: A Theoretical and Empirical Adjustment to the Human Empowerment Sequence." Journal of Cross-Cultural Psychology.

Dunn, Kris, and Shane P. Singh. 2011. "The Surprising Non-impact of Radical Right-wing Populist Party Representation on Public Tolerance of Minorities." Journal of Elections, Public Opinion \& Parties 21 (3):313-31.

—. 2014. "Pluralistic Conditioning: Social tolerance and effective democracy." Democratization 21 (1):1-28.

Dunn, Kris, Viktoria Spaiser, and Harvey J. Dodds. 2020. "The Role of Threat in the Human Empowerment Sequence." https://doi.org/10.31234/osf.io/3zun4. 
Etzioni, Amitai. 2000. "Social norms: Internalization, persuasion, and history." Law \& Society Review 34 (1):157-78.

Federico, Christopher M., Emily L. Fisher, and Grace Deason. 2017. "The Authoritarian Left Withdraws from Politics: Ideological Asymmetry in the Relationship between Authoritarianism and Political Engagement." The Journal of Politics 79 (3):101023.

Feldman, Stanley. 2003. "Enforcing social conformity: A theory of authoritarianism." Political Psychology 24 (1):41-74.

Feldman, Stanley, and Karen Stenner. 1997. "Perceived threat and authoritarianism." Political Psychology 18 (4):741-70.

Freedomhouse.org. 2018. "Freedom in the World 2018." Online: Freedom House.

Frenkel-Brunswik, Else, Daniel J. Levinson, and R. Nevitt Sanford. 1947. "The Antidemocratic Personality." In Readings in Social Psychology, ed. E. E. Maccoby, T. M. Newcomb and E. L. Hartley. New York: Henry Holt \& Co.

Fromm, Erich. 1941. Escape from freedom. New York: Farrar \& Rinehart.

Gordon, Peter E. 2017. "The Authoritarian Personality Revisited: Reading Adorno in the Age of Trump." boundary 244 (2):31-56.

Hetherington, Marc J., and Elizabeth Suhay. 2011. "Authoritarianism, threat, and Americans' support for the War on Terror." American Journal of Political Science $55(3): 546-60$.

Hetherington, Marc J., and Jonathan Daniel Weiler. 2009. Authoritarianism and Polarization in American Politics. Cambridge; New York: Cambridge University Press. 
Inglehart, Ronald, Christian Haerpfer, Alejandro Moreno, Christian Welzel, Kseniya Kizilova, Juan Díez Medrano, Marta Lagos, Pippa Norris, Eduard Ponarin, and Bi Puranen. 2014. "World Values Survey: Round Six - Country-Pooled Datafile 20102014.". Madrid: JD Systems Institute.

Inglehart, Ronald, and Pippa Norris. 2017. "Trump and the Populist Authoritarian Parties: The Silent Revolution in Reverse." Perspectives on Politics 15 (2):443-54.

Lipset, Seymour Martin. 1959. "Democracy and Working-Class Authoritarianism." American Sociological Review 24 (4):482-501.

— 1960. Political Man: The social bases of politics. Garden City, N.Y.: Doubleday. MacWilliams, Matthew C. 2016. "Who Decides When The Party Doesn't? Authoritarian Voters and the Rise of Donald Trump." PS: Political Science \& Politics 49 (4):71621.

Markoff, John. 2011. "A moving target: Democracy." European Journal of Sociology 52 (02):239-76.

McClosky, Herbert. 1964. "Consensus and ideology in American politics." The American Political Science Review 58 (2):361-82.

McClosky, Herbert, and John Zaller. 1984. The American Ethos: Public attitudes toward capitalism and democracy. Cambridge, Mass.: Harvard University Press.

McCoy, Jennifer, Tahmina Rahman, and Murat Somer. 2018. "Polarization and the Global Crisis of Democracy: Common Patterns, Dynamics, and Pernicious Consequences for Democratic Polities." American Behavioral Scientist 62 (1):1642. 
Mudde, Cas. 2013. "Three decades of populist radical right parties in Western Europe: So what?" European Journal of Political Research 52 (1):1-19.

Norris, Pippa. 1999. Critical Citizens: Global support for democratic government. Oxford; New York: Oxford University Press.

Oyamot, Clifton M., Emily L. Fisher, Grace Deason, and Eugene Borgida. 2012. "Attitudes toward immigrants: The interactive role of the authoritarian predisposition, social norms, and humanitarian values." Journal of Experimental Social Psychology 48 (1):97-105.

Oyamot, Clifton M., Melinda S. Jackson, Emily L. Fisher, Grace Deason, and Eugene Borgida. 2017. "Social Norms and Egalitarian Values Mitigate Authoritarian Intolerance Toward Sexual Minorities." Political Psychology 38 (5):777-94.

Pappas, Takis S. 2016. "Distinguishing Liberal Democracy’s Challengers " Journal of Democracy 27 (4):22-36.

Peterson, Bill E., and Eileen L. Zurbriggen. 2010. "Gender, Sexuality, and the Authoritarian Personality." Journal of Personality 78 (6):1801-26.

Prothro, James W., and Charles M. Grigg. 1960. "Fundamental principles of democracy: Bases of agreement and disagreement." The Journal of Politics 22 (2):276-94.

Puddington, Arch, Jennifer Dunham, Elen Aghekyan, Christopher Brandt, Rukmani Bhatia, Isabel Linzer, Shannon O'Toole, Sarah Repucci, and Tyler Roylance, eds. 2019. Freedom in the World 2018: The Annual Survey of Political Rights \& Civil Liberties. London, U.K.: Rowman \& Littlefield

Rupnik, Jacques. 2016. "Surging Illiberalism in the East." Journal of Democracy 27 (4):7787. 
Sartori, Giovanni. 1997. "Understanding pluralism." Journal of Democracy 8 (4):58-69.

Singh, Shane P., and Kris Dunn. 2013. "Veto players, the policymaking environment, and the expression of authoritarian attitudes." Political Studies 61 (1):119-41.

ـ 2015. "Authoritarianism, socioethnic diversity and political participation across countries." European Journal of Political Research 54 (3):563-81.

Stenner, Karen. 2005. The Authoritarian Dynamic. New York, NY: Cambridge University Press.

_ 2009. "Three kinds of "conservatism"." Psychological Inquiry 20 (2-3):142-59.

Weiner, Elliot, and Christopher M. Federico. 2017. "Authoritarianism, Institutional Confidence, and Willingness to Engage in Collective Action." Personality and Social Psychology Bulletin 43 (3):392-406.

Welzel, Christian. 2013. Freedom Rising: Human empowerment and the quest for emancipation. New York, NY: Cambridge University Press.

Wike, Richard, and Janell Fetterolf. 2018. "Liberal Democracy’s Crisis of Confidence." Journal of Democracy 29 (4):136-50.

Zakaria, Fareed. 1997. "The Rise of Illiberal Democracy." Foreign Affairs 76 (6):22-43. 